\title{
The most important lessons I learned in training
}

\author{
Michael P. Robich, MD
}

\author{
From the Cardiovascular Institute, Maine Medical Center, Portland, Me. \\ Disclosures: M.P.R. is a surgical proctor and invited lecturer for the Perceval aortic valve prosthesis, LivaNova \\ Received for publication Dec 15, 2016; revisions received March 6, 2017; accepted for publication April 12, 2017 ; \\ available ahead of print May 18, 2017. \\ Address for reprints: Michael P. Robich, MD, 818 Congress St, Portland, ME 04102 (E-mail: mrobich@ \\ mmc.org). \\ J Thorac Cardiovasc Surg 2017;154:1015-6 \\ $0022-5223 / \$ 36.00$ \\ Copyright (c) 2017 by The American Association for Thoracic Surgery \\ http://dx.doi.org/10.1016/j.jtcvs.2017.04.027
}

I completed cardiothoracic surgery training in 2015 , and the transition from training to practice has offered me the opportunity for reflection. Much is practical, such as how to be more efficient in the operating room and in the clinic, which new technologies should be added to my practice (and when), and how to build and work well with a strong team. Through the decade-long path that now allows me to do what I love, I have been able to reflect on my training. The journey was not easy, and I am thankful that it was not, as the hard lessons and hard work were important to my growth as a person and as a surgeon. I took the traditional pathway to become an adult cardiac surgeon, which included 5 years of general surgery training, 2 years in a laboratory fellowship, and 3 years of cardiothoracic training. Throughout each phase of training, formative lessons were learned that shaped who I am today.

I completed general surgery residency at the Beth Israel Deaconess Medical Center in Boston, where I learned the principles of surgery, including how to manage sick patients. During intensive care unit rotations, we were expected to be in the intensive care unit and rounding throughout the day and night. The decision to leave the hospital was based on the patient's condition, not on the clock. The age-old idioms of surgery became reality during this phase of my training: read it yourself, look at it yourself, do it yourself, always prepare, and have a system in place to stay organized. A case that embodies this well is that of an off-duty firefighter who was struck by a car while assisting a disabled vehicle on Storrow Drive in Boston. He arrived critically ill, with multiple orthopedic, vascular, and abdominal injuries, and was taken to the operating room, where the trauma, vascular, and orthopedic teams worked together to stabilize him. He underwent multiple operations during the next week. Acute management gave way to the chronic problems from being in the intensive care unit: infection, renal failure, seizures that required a phenobarbital coma, tracheostomy, and feeding access. There were times while caring for this patient when I wondered, even with all the work and technology—could we save him? He eventually left the hospital for rehabilitation while he was still receiving mechanical

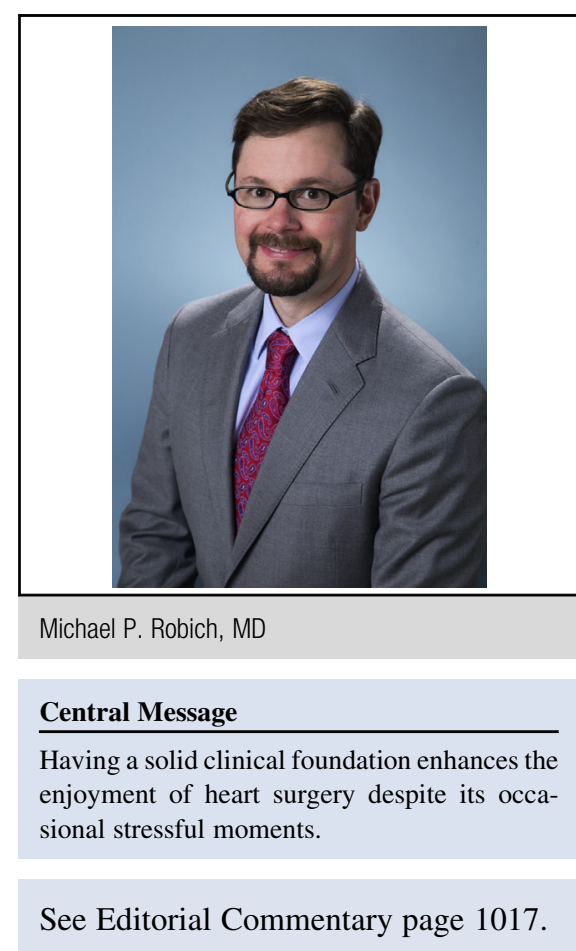

ventilation. Several months later, he returned to visit-in a wheelchair-very grateful and happy to be alive. I do not think that I could have learned fastidious management, attention to detail, and high expectations in a different manner. Like many of us, my current practice includes patients with high acuity level, including those with advanced heart failure, and a number of whom require mechanical support; I find that these skills have been beneficial in preoperative and postoperative management.

I spent 2 years as a laboratory fellow studying therapeutic angiogenesis. That fellowship was exciting as we developed a swine model of metabolic syndrome and chronic myocardial ischemia. I had the opportunity as a midlevel general surgery resident to catheterize and perform heart operations on pigs, with the outcomes scrutinized as carefully as they are in human patients. Our findings from this work paved the way for the translational research that I conduct today. One of the most valuable skills developed more fully during this period was that of being inquisitive. I brought my heightened curiosity from the laboratory to the clinical setting, where I asked more questions, looked for problems to solve, and sought to understand and address shortcomings in our clinical practice. A different and enjoyable dimension was thus added to my bedside and operating room experience. 
My final phase of postgraduate training was a cardiothoracic residency at the Cleveland Clinic. During 3 years of intense clinical work, my strong love for operating developed. I believe that the passion for heart surgery when you are practicing on your own is founded on solid clinical training. Creating this passion involved taking on a large volume of cases that helped me to learn skills, develop a system, lead a team, and deal with problems in the operating room and on the wards. Being guided by 16 staff surgeons showed me many ways to tackle glitches, hitches, and complications. Of course, one early goal was to learn how to avoid problems, but when the common issues arise, I feel that I have a framework to solve them. I plan each case carefully and identify potential problematic steps. A lot of the anxiety of operating can be relieved when there is a progression of solutions-a plan B and beyond-in your mind. There have certainly been occasions, however, when I do not have another move and am not sure what to do. In that case, I take a breath, gain some control, and try to think through the problem. If I cannot figure the problem out quickly, it is time to call for help. Now that I am in practice, I have found my new partners to be available to offer advice or scrub in to help when necessary, often providing great learning opportunities.

Beginning life as a new surgeon in a new hospital was tough. Everybody was watching, and expectations were high. My partners were supportive to provide every opportunity for success. At the end of the day, though, it was up to me to make the transition from surgeon in training to attending surgeon. I remember my first solo operation clearly, a straightforward coronary artery bypass grafting procedure. Despite my anxiety, the muscle memory and skills I had learned kicked in, and the case went smoothly. I still recall how great it felt to take the clamp off and watch the heart start beating again. Subsequently, cases increased in number and complexity. In the first year of practice, it seems there is no shortage of new, unfamiliar, and anxiety-provoking situations. Every surgeon goes through the same formative events: first complication, first death, and challenging decisions, patients, and families. Although we have all been through these occasions, it can feel very lonely at times, and I find myself grateful for all the exceptional surgeons who have worked through these difficult problems before and paved the way. Thankfully, in our modern practice, delivering good news is far more common than bad. Having a solid clinical foundation enhances the enjoyment of heart surgery despite its occasional stressful moments. I have a fantastic team, and we work hard. I was able to complete 247 cases my first year and learned an extraordinary amount of invaluable practical knowledge. A challenge that I face already, just over a year out from training, is how to incorporate new technology. Although a focus on outcomes with standard surgery is paramount, innovation in our field is moving fast. I imagine that almost every training program offers opportunities to learn some advanced techniques. I was fortunate to become comfortable with minimally invasive surgery, transcatheter aortic valve replacement, thoracic endovascular aneurysm repair, temporary and durable left ventricular assist devices, and sutureless valve technology, but I did not have any real experience with convergent maze, robotics, or percutaneous mitral techniques. I do not think that we can expect programs to teach everything, but we need a framework for how to evaluate new options. I am glad that I was able to witness this process as a trainee to keep an open but critical mind regarding industry and innovative procedures. I am looking to incorporate 1 or 2 new technologies into practice during the year, and I look for support from my partners, mentors, and colleagues who are using these new methods.

It took 10 years of postgraduate training to arrive at the beginning of my career as an attending cardiac surgeon. My father worked in the automotive industry, and when I was young we had a Fram oil filter that had been made into a piggy bank. On the side it had the quotation, "Pay me now or pay me later." This slogan resonated with me, and it became the infrastructure for my work ethic. I put in maximum effort and time to absorb knowledge and skills in training to avoid, as much as possible, "paying later" in the form of increased stress from unfamiliar situations and knowledge gaps. At some point, we have each had to learn the technical aspects and decision making of this job. It was exhausting, but as I started practice, I realized that it had paid off. There is increasing pressure during training to be out of the hospital and to participate in nonclinical activities such as administration and documentation. Although these tasks are important, becoming a safe and competent surgeon should be considered the most important. You can learn how to manage hypertension or understand renal physiology from a book, but surgery is best learned in the operating room.

I will be the first to admit that I did not succeed well at balancing my life while a trainee. Having 2 sons and getting into practice helped my work-life balance tremendously. I make an effort to get home for dinner 3 nights a week and spend quality time with the family. To achieve this, I attempt to schedule cases thoughtfully to avoid doing 2 complex cases in one day. I use a 1 to 3 numbering system (from most straightforward to most complex), so that my nurse and secretary can plan proficiently. We try to schedule no more than a total score of 3 on a given day, and only 2 with a score of 1 on late-start days in the operating room. I cannot take credit for developing this system. Eric Roselli introduced it to me and I have been happy with it. It has afforded more time to rediscover hobbies that I gave up long ago: skiing, travel, reading (nonmedical books), and golf. It feels good.

I am very grateful to all the surgeons who trained me and showed incredible patience. During this time, I feel that I have matured as a person and a surgeon. At each phase, I learned lessons of great value: good patient care, inquisitiveness that can improve our field, and a passion for cardiothoracic surgery. 